Review

\title{
Lights and Shadows in Hepatic Encephalopathy Diagnosis
}

\author{
Piero Amodio*(1) and Sara Montagnese \\ Department of Internal Medicine, DIMED, University of Padova, I-35100 Padova, Italy; \\ sara.montagnese@unipd.it \\ * Correspondence: piero.amodio@unipd.it; Tel.: +39-03-9780-1153
}

Citation: Amodio, P.; Montagnese, S. Lights and Shadows in Hepatic Encephalopathy Diagnosis. J. Clin. Med. 2021, 10, 341. https://doi.org/ $10.3390 /$ jcm10020341

Received: 18 December 2020

Accepted: 15 January 2021

Published: 18 January 2021

Publisher's Note: MDPI stays neutral with regard to jurisdictional claims in published maps and institutional affiliations.

\begin{abstract}
Hepatic encephalopathy (HE) is a form of brain dysfunction that is caused by liver insufficiency and/or portal-systemic shunting. The exact nature of HE is debated; as such, conflicting uses of the term "HE" may cause inconsistencies in its detection and management. This review highlights the meaning of the term "HE" on the basis of its historical origins and current consensus. It also provides criteria for the diagnosis of the condition based on its phenotypes and risk factors for its occurrence. The procedure for differential diagnosis from other conditions which result in similar phenotypes is considered, together with precipitants and confounders. Finally, the current multidimensional approach for the correct clinical reporting of HE episodes is discussed.
\end{abstract}

Keywords: liver failure; encephalopathy; delirium; coma; cirrhosis

\section{Introduction}

The diagnosis of hepatic encephalopathy $(\mathrm{HE})$ is relevant as it is a marker of poor survival in cirrhosis and acute liver failure (ALF) [1,2], and is a disabling condition resulting in poor quality of life for patients and their caregivers [3]. Further, HE incurs significant direct costs to health service systems [4], as it is the second leading cause of hospitalization in patients with cirrhosis and the primary reason for re-hospitalization [5]. It also results in considerable indirect costs related to loss of work for patients and caregivers [6]. A correct diagnosis is required in order to select proper treatment, prevent further episodes in individual patients, and conduct meaningful prevention/treatment trials.

While the diagnosis of HE may seem simple (and frequently this is the case), the diagnosis can be complex and uncertain. The issue is not trivial and firstly depends on what one considers to be HE; i.e., on its definition.

\section{The Meaning of the Term "HE"}

The recognition of an association between jaundice and behavioral alterations is ancient, while that between cirrhosis and confusion/stupor is some three centuries-old, and the pathophysiological explanation for these associations dates back to end of the nineteenth century [7].

On this basis, the American Association for the Study of Liver Disease (AASLD)/ European Association for the Study of the Liver (EASL) practice guidelines for HE define $\mathrm{HE}$ as "Brain dysfunction caused by liver failure and/or portal-systemic shunting (PSS); it manifests as a wide spectrum of neurological or psychiatric abnormalities ranging from subclinical alterations to coma" [8]. The term "hepatic" is used to underline a specific pathophysiological link to liver failure and/or portal-systemic shunting.

However, the habit of calling encephalopathy "hepatic" on the basis of a "clinical suspicion" in patients with liver disease remains [9-12]. This is open to criticism, since seldom in medicine is encephalopathy qualified based on the disease in which it occurs. By contrast, it is generally qualified based on the pathophysiological mechanism causing encephalopathy/delirium in order to direct etiological treatment. Thus, the terms 
"lung encephalopathy" or "cardiac encephalopathy" do not exist, while the terms "hypercapnic encephalopathy", "hypoxemic encephalopathy", and "cerebral hypoperfusion encephalopathy" are used.

Thus, if "hepatic" does not refer to a specific mechanism, it would be better replaced by a term that does (i.e., "patient with cirrhosis and benzodiazepine intoxication", "opioid overdose", "hyponatremic encephalopathy", "septic encephalopathy", or "hyperammonemic encephalopathy", etc.). This would avoid misinterpretation and mismanagement due to the use of the same treatment for conditions with different underlying types of pathophysiology.

As an analogy, using the term HE in a broad meaning would be the same as calling fever in patients with cirrhosis "hepatic fever", regardless of its cause (i.e., pneumonia, urinary tract infection, spontaneous bacterial peritonitis, etc.), and treating it in the same way. The idea that in patients with cirrhosis all encephalopathies should be classified and managed depending on their etiology was clearly formulated by Riddell around 65 years ago [13]: " . . among a group of patients with severe liver disease a number of neurological disturbances will be met with; not all of these are the disease known as hepatic coma. Among these other states are the psychoses associated with chronic alcoholism and nicotinic acid deficiency, electrolyte disturbances, septicaemia, increased response to narcotics and subdural haematoma."

Considering the definition given by the AASLD/EASL practice guidelines, the following question may arise: "Which type of brain dysfunction is caused by liver failure and/or PSS?". This question implies the detection of a mechanism that specifically links these conditions. Such a link between a failing liver and/or PSS and encephalopathy concerns abnormalities in nitrogen metabolism, as the liver has a unique role in the detoxification of ammonia and most other substances coming from the gut. This has been proven by the observation of dogs undergoing portal-caval shunting who (1) developed encephalopathy after the consumption of ammonia salts and nitrogen-containing-foods, (2) reduced their urinary urea excretion, and (3) reduced their capacity to synthetize urea from gastric-infused carbamic acid [14]. Further, the oral administration of ammonium chloride to cirrhotic patients causes coma [15], and the toxicity of ammonia to the human brain has been proven by cognitive defects with respect to attention/executive function and coma in individuals with hereditary defects in urea cycle enzymes [16]. Finally, the creation of large portal-systemic shunts causes hyperammonemia and encephalopathy in humans, and shunt obliteration reduces ammonemia and improves HE [17].

PSS and hepatic failure may cause an increase in any neurotoxic substance originating from the gut that has a high first-pass hepatic metabolism, like ammonia. Research on this has been limited over the past years, after emphasis was given to the topic by Zieve [18]. Substances with the above features which may have a pathophysiological role in HE include: (1) manganese (particularly in the motor disturbances associated with HE), since this heavy metal deposits in the basal ganglia due to its reduced clearance in portalsystemic shunting and cholestasis [19], and (2) indole, that crosses the blood-brain barrier and produces oxindole within the brain, which is a neurotoxic substance [20]. Further, gut dysbiosis, Kuppfer cell dysfunction [21], and portal-systemic shunt may favor systemic inflammation, which also affects brain function [22,23].

It should be emphasized, however, that despite hyperammonemia being a necessary condition for the occurrence of HE (and thus subjects without hyperammonemia should be suspected of having a delirium of alternative origin), hyperammonemia is common in cirrhosis, mainly because of PSS [24], and its occurrence does not imply a phenotypical HE expression. Indeed, ammonia interacts with other factors to disturb brain function [25]. This explains why the clinical expression of HE is only roughly related to ammonia plasma levels, since individual susceptibility to developing a hyperammonemia-related phenotype depends on several factors. Thus, in the same individual, changes in co-factors may change the effect of ammonia, and varying brain susceptibility to the levels of ammonia was proven long ago [15]. More recently, an elegant study by Shawcross and co-authors [26] proved the different effects of ammonia depending on cytokine levels. We ourselves have shown 
that same levels of ammonia have different effects on brain electrogenesis depending on sodium levels [27].

This limits the value of using absolute isolated ammonia levels as an index of HE. However, the diagnostic value of plasma ammonia is high, since normal ammonia levels suggest that the degree of liver failure/shunt is insufficient to support a working diagnostic hypothesis of HE. A recent study [11] seems to contradict this view, showing that recovery of normal mental state is the same in patients with delirium and ammonia levels higher or lower than $75 \mathrm{mmol} / \mathrm{L}$ (the upper limit of normality) [24]. Of note, $80 \%$ of these patients had a history of overt HE. However, the patients with low ammonia levels had a higher rate of infection than the others. In addition, in all patients the precipitating factor of the HE episode was treated, and it is reasonable to expect that this would have resulted in clinical improvement. The use of lactulose in all patients was probably irrelevant to the conclusions of the study, since it is useful in patients with $\mathrm{HE}$ and innocuous in those with other kinds of delirium.

HE in acute liver failure is a distinct type of HE [8] that occurs in the context of systemic hemodynamic alteration and multi-organ failure (MOF) $[28,29]$; thus, it has separate features in which brain swelling due to acute hyperammonemia and intracranial hypertension have a peculiar role.

Recently, it has been observed that HE in acute-on-chronic liver failure also has some peculiar features [30,31]. It frequently occurs in sepsis, cytokine storm, and MOF that reasonably produce overlapping metabolic/hemodynamic encephalopathies. These may deserve to be considered separately and frequently require multitarget treatment in managed intensive care unit (ICU) patients.

In all cases of encephalopathy, especially in the context of ALF or acute-on-chronic liver failure (ACLF), the exclusion of alternative causes is mandatory because an incorrect, missed, or delayed alternative diagnosis (e.g., brain hemorrhage) has profound consequences.

\section{The Diagnosis of HE}

The diagnosis of $\mathrm{HE}$, as with every clinical diagnosis, results from the a priori probability of HE before any observation, and the probability that a clinical finding relates to HE. This should be compared with the probability of alternative conditions.

Thus, the degree of certainty for the diagnosis of HE depends on three key steps: (1) the a priori probability of $\mathrm{HE}$, (2) the recognition of a clinical pattern suggestive of $\mathrm{HE}$, and (3) the consideration of alternative conditions.

In formal Bayesian terms:

Odds of HE $=$ a priori odds of HE prevalence $\times$ positive likelihood ratio of clinical findings for HE vs. a priori odds of alternative condition prevalence $\times$ positive likelihood ratio of clinical findings for alternative conditions.

However, formal Bayesian estimations cannot be performed, because an exact quantification of the parameters of the equation is not available and varies reasonably depending on the clinical settings. However, the clinician's reasoning is still Bayesian and the related questions are as follows: Is the presentation suggestive of HE? Is it probable that in this patient HE may occur? Are there other conditions that may explain this clinical presentation?

The a priori probability of HE depends on the severity of liver failure [32,33] and/or the extent of PSS [34], in addition to the history of previous episodes of overt HE [27]. Recently, a clinical score was proposed to assess the risk for the first episode of overt HE [11].

Of note, the severity of liver failure and PSS have a fundamental role, and they are associated with high levels of plasma ammonia. This is a known risk factor for HE [35,36].

The a priori probability is increased by the occurrence of precipitating factors for $\mathrm{HE}$, even if their prevalence varies considerably between the studies (Table 1). 
Table 1. Prevalence (percentage and 95\% CI) of precipitating factors for hepatic encephalopathy (HE).

\begin{tabular}{|c|c|c|c|c|}
\hline & $\begin{array}{l}\text { Ali et al. [37] } \\
\qquad N=100\end{array}$ & $\begin{array}{l}\text { Cordoba et al. [31] } \\
\qquad(N=460)\end{array}$ & $\begin{array}{l}\text { Devrajani et al. [38] } \\
\qquad(N=87)\end{array}$ & $\begin{array}{l}\text { Stauss et al. [39] } \\
\quad(N=168)\end{array}$ \\
\hline Infections & $20(13-29)$ & $26(22-30)$ & $67(56-76)$ & $31(24-38)$ \\
\hline Bleeding & $14(8-22)$ & $11(9-14)$ & $45(35-55)$ & $20(15-27)$ \\
\hline Constipation & $37(28-47)$ & - & $40(39-60)$ & \\
\hline DDEI * & $70(60-78)$ & 89 (86-91) & $54(44-64)$ & $36(29-44)$ \\
\hline Acute alcoholism & & $17(14-20)$ & - & $2(1-6)$ \\
\hline Not recognized & $11(6-19)$ & - & $6(2-13)$ & $10(6-15)$ \\
\hline
\end{tabular}

DDEI *: Dehydration, diuretics, electrolyte imbalance; CI: confidence interval. Note: the sum of the percentages may be higher than 100 because of overlap.

Precipitating factors can be considered as those conditions which intervene in the pathophysiology of HE by increasing the production of ammonia, reducing its disposal or increasing its neurotoxicity. For instance, gastrointestinal bleeding and constipation increase ammonia production, and inflammation (especially that associated with infections) and hyponatremia increase ammonia toxicity $[26,27,40]$. Of note, infections, as well as hypothyroidism, increase ammonia production $[13,37]$.

In contrast to precipitants, conditions that alter brain function by a direct mechanism, independent of liver nitrogen metabolism, can be called confounders (Figure 1).

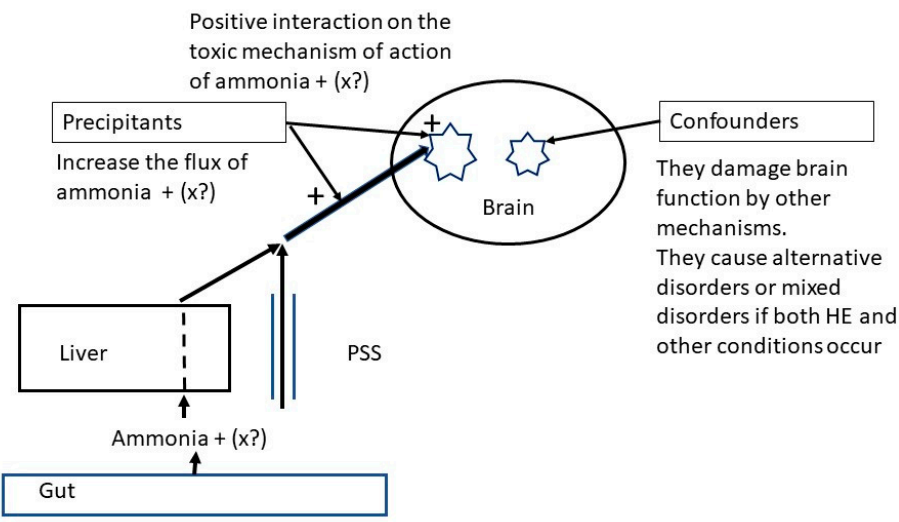

Figure 1. Schema showing the different concepts of precipitants and confounders.

It should be considered that the distinction between precipitants and confounders is not always simple or clear. Some factors such as sepsis, hyponatremia, and hypothyroidism, which function as precipitants (because they intervene in the mechanisms of ammonia production or toxicity), can also alter brain function per se, as occurs in patients without liver failure [41-44]. Treatment should be directed at these factors and not only at hyperammonemia [8].

The recognition of the clinical presentation that $\mathrm{HE}$ is an obvious pre-requisite for its diagnosis. HE may manifest as coma, delirium of various degrees (mainly sedated, but sometimes agitated) [8], and sometimes with transient focal symptoms [45]. Further, HE may present as an almost continuous cognitive dysfunction, interspersed with more or less severe episodes of delirium [8]. A mild presentation of HE mimics persistent or episodic non-amnestic minimal cognitive dysfunction or disinhibition [46]. Finally, motor signs can be associated or (rarely) dominate the presentation. The most obvious and common is negative myoclonus, which produces the classical finding of asterixis. Other motor findings are extrapyramidal manifestations such as parkinsonism [47], chorea and hemiballismus [48], or spastic paraparesis [49]. These symptoms, generally found in association with large PSS, are called non-Wilsonian hepatocerebral degeneration and hepatic myelopathy [46]. These conditions, however, can be considered subtypes of HE as both are superimposed, and portal-systemic shunting which intervenes in their pathophysiology and overlap with mild confusion is the rule (Table 2). 
Table 2. Phenotypes of HE.

\begin{tabular}{|c|c|c|}
\hline Pattern & & Description \\
\hline (A) Coma (grade 4 West Haven classification) & & $\begin{array}{l}\text { The patient's eyes are closed; they are unresponsive even to } \\
\text { painful stimulation. }\end{array}$ \\
\hline \multirow[t]{2}{*}{$\begin{array}{l}\text { (B) Rapidly developing state of confusion (delirium)(grade 2-3 } \\
\text { according to the West Haven classification) }\end{array}$} & Inhibited & $\begin{array}{l}\text { The patient is more or less disoriented in time and/or space } \\
\text { and/or identity and is more or less somnolent/stuporous. } \\
\text { Asterixis is usually detectable. }\end{array}$ \\
\hline & Agitated & $\begin{array}{l}\text { The patient is disoriented in time and/or space and/or identity } \\
\text { and is agitated/angry/restless. Asterixis is usually detectable }\end{array}$ \\
\hline $\begin{array}{l}\text { (C) Almost continuous mild mental dysfunction with } \\
\text { interspersed recurrent episodes of confusion(persistent/almost } \\
\text { continuous HE with frequent relapses) }\end{array}$ & & The pattern is dementia-like. Asterixis is usually detectable. \\
\hline \multirow{2}{*}{$\begin{array}{l}\text { (D) Predominant motor disorder with mild/moderate mental } \\
\text { dysfunction/confusion(corresponds to the conditions of hepatic } \\
\text { parkinsonism and hepatic myelopathy/non-Wilsonian } \\
\text { hepatocerebral degeneration) }\end{array}$} & Extrapyramidal & $\begin{array}{l}\begin{array}{l}\text { Parkinsonism, chorea, or athetosis. Asterixis is usually } \\
\text { detectable. }\end{array}\end{array}$ \\
\hline & Pyramidal & $\begin{array}{c}\text { Spastic paraparesis with hyperreflexia. Asterixis is usually } \\
\text { detectable. }\end{array}$ \\
\hline (E) Mild brain dysfunction & & $\begin{array}{l}\text { The patient is oriented for time and space and his/her mental } \\
\text { activity seems normal/near-normal; however, caregivers or } \\
\text { heath personnel may recognize a deterioration of the patient in } \\
\text { terms of behavior, irritability, and cognition.Upon psychometric } \\
\text { testing, alterations are detectable (related to attention, working } \\
\text { memory, cognitive speed, and inhibition). Other signs, } \\
\text { associated or independent of psychometrical alterations, include } \\
\text { slowed electroencephalographyc activity and/or reduced } \\
\text { critical flicker frequency. Dissociations between the techniques } \\
\text { are frequent. }\end{array}$ \\
\hline
\end{tabular}

Accordingly, for the differential diagnosis of the clinical findings compatible with HE [50], one should briefly consider the probability of alternative/overlapping causes of the clinical findings: coma, delirium, transient focal attacks, persistent undulating dementia-like mental decay, and motor disorders [51-55]. The occurrence of sudden coma requires brain imaging, since hemorrhagic stroke has an increased prevalence in liver failure [56]. Similarly, the occurrence of persistent/highly recurrent HE may require the search for additional/alternative causes of dementia or neurodegenerative disorders by brain imaging and extensive investigation.

Of note, the occurrence of a finding compatible with HE and a high a priori probability does not exclude the existence of mixed encephalopathy. Indeed, the addition of various factors damaging brain function facilitates the occurrence of symptoms. In the case of a mixed encephalopathy, the treatment of the brain dysfunction caused by HE may result in an improvement, but does not completely revert the clinical picture [57].

A chart that summarizes the diagnostic process is reported in Figure 2.

Additionally, if HE is present and is the only cause of the clinical findings (thus, what is $H E$ and what is not $H E$ ), the diagnosis of $\mathrm{HE}$ requires some additional attributes relating to its type, severity, rate of recurrence, precipitant, and facilitating factors [58]. Thus, a complete diagnosis should be multidimensional (as was first suggested by Ferenci et al. [10] and emphasized in the practice guidelines of the AASLD/EASL [8] and the Italian association for the Study of the Liver AISF [58]).

Of note, recent brain imaging techniques [59-61] and accurate microbiome and metabolomic studies [62] are providing important new insights on HE, but at the moment these techniques are limited to research purposes.

Conflicting opinions concern the diagnosis and quantification of mild forms of $\mathrm{HE}$. In the 1950s Parsons-Smith et al. [63] recognized two important findings: (1) some patients with cirrhosis may have subtle mental changes and psychometrical alterations in the absence on unequivocal neurological signs, and (2) patients without any alterations may have EEG abnormalities. These authors clearly showed that HE can produce (1) mild equivocal mental/cognitive/behavioral alterations, and (2) even neurophysiological alterations without any other evidence. Conn et al. [64] provided a quantification of mental changes in HE, slightly modifying that of Parsons-Smith et al. [63], and classified grade $1 \mathrm{HE}$ as a condition characterized by subtle cognitive/behavioral alterations without disorientation (in time or space). Since then, new techniques of investigation of cognitive investigation 
(based on techniques requiring patient cooperation) and brain function (i.e., independent of patient's cooperation) have been developed, with a plethora of definitions and names provided, including latent $\mathrm{HE}$, subclinical $\mathrm{HE}$, minimal $\mathrm{HE}$, and grade $1 \mathrm{HE}$. Basically, there is an agreement that (1) some patients do not show any clinical symptoms/signs of HE but do have neurophysiological or psychometrical alterations, and (2) other patients have "something wrong" in their awareness, behavior, or attention that can be recognized by skilled clinicians and caregivers. The former condition is preferably called minimal HE, whereas the latter is grade $1 \mathrm{HE}$. However, since both conditions are not unequivocal (at odds with frank disorientation) and the line between the two depends on the sensitivity of the observer, a proposal was made $[8,65]$ to gather the two conditions under the heading of "covert" HE (mainly because the sound "covert" evokes the antonym of "overt"), considering that this condition requires quantification by objective tests. This proposal aimed to avoid possible inter-observer disagreement and inconsistency in the detection of grade $1 \mathrm{HE}$. At any rate, possible confusion arises if "covert" is misinterpreted as a synonym of minimal, or if mildly symptomatic HE (grade " 1 ") is considered to overlap with asymptomatic HE (i.e., minimal HE). Thus, conflicting opinions still exist about the use of the terms.

Operative definition for the diagnosis of grade $1 \mathrm{HE}$ was provided by Vilstrup et al. [8]. The diagnosis of minimal HE requires proper testing. This can be neurophysiological, (e.g., quantified electroencephalogram, evoked potentials, etc.), psychophysiological (e.g., critical flicker frequency), or neuropsychological [66,67]. Of note, psychometrical testing needs to be oriented to the cognitive domains mostly altered by the initial phase of HE (e.g., cognitive speed, divided attention, sustained attention, inhibition, working memory) and be properly standardized for single patients, since cognitive performance depends on age and education and, most probably, geographical/national factors [66]. Thus, locally standardized Z-score based techniques, such as the psychometric HE score PHES [68], are preferable. Recently, a very rapid oral technique based on animal naming has been suggested [69], but needs confirmatory studies. Computerized tests based on chronometric techniques have been used [70-72] and may be more repeatable since they are based on the repetition of many trials, but only well-educated, cooperative individuals can be easily tested. Further, any kind of mild psychometrical/neurophysiological dysfunction in cirrhosis cannot be immediately attributed to minimal $\mathrm{HE}$, since mild cognitive dysfunction can have many concurrent causes [73,74].

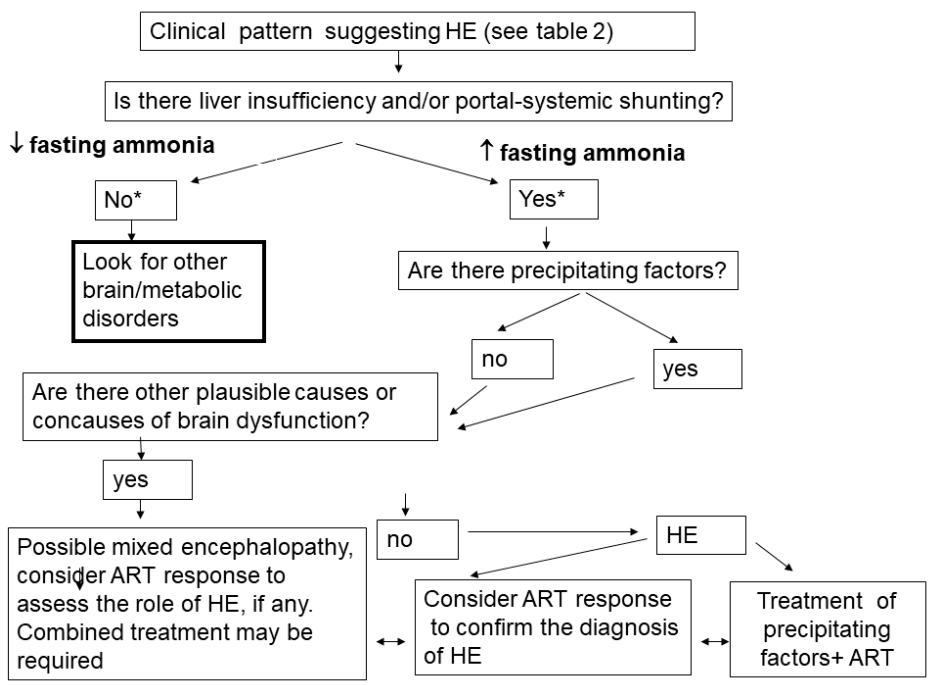

Figure 2. Flow chart for the diagnosis of hepatic encephalopathy (HE) (modified from [50]). ART: ammonia-reducing treatment (non-absorbable antibiotic \pm disaccharides). ${ }^{*}$ Low ammonia is considered to have high negative predictive value for HE [8], since it suggests: (1) relatively good liver function, (2) negligible portal-systemic shunting, and (3) negligible gut dysbiosis in cirrhosis. 


\section{Conclusions}

The existence of liver failure, PSS, prior HE, frailty, and precipitating factors increase the risk of HE. However, the risk provided by these conditions (with varying degrees) cannot be exactly quantified, and neither can the risk provided by their interaction. At present, therefore, they may only confer a subjective degree of confidence relating to the a priori likelihood for the diagnosis of HE.

Another milestone for diagnosis depends on the recognition of the phenotype of HE [50], which is unspecific. Thus, alternative or concurrent conditions should be considered, particularly for patterns where a rapid alternative diagnosis may have high relevance with regard to the outcome (for example coma). Other conditions that require intensive work are the presentations characterized by prominent motor features or persistent fluctuating mental alterations. In most cases the diagnosis is simple, particularly when there is strong a priori probability that the patient only has liver disease and the phenotype of $\mathrm{HE}$ is one of delirium. In other conditions, the diagnosis can be more challenging. It is reasonable to assume that $\mathrm{HE}$ can be confirmed if a full-dose regime of non-absorbable disaccharides and non-absorbable oral antibiotics (i.e., a regimen significantly reducing plasma ammonia) improves or completely reverts symptoms in a few days. Finally, after having reached a correct diagnosis of the existence of $\mathrm{HE}$, multidimensional qualification is required to characterize the type, severity, time course, and precipitant-favoring factors, in accordance with present practice guidelines.

Author Contributions: The authors (P.A. and S.M.) cooperated equally towards the production of the article that reflects their research and views on HE. The final draft was prepared by P.A. All authors have read and agreed to the published version of the manuscript.

Funding: This review did not receive any external funding.

Data Availability Statement: No new data were created or analyzed in this study. Data sharing is not applicable to this article.

Acknowledgments: The authors are grateful to all the coworkers and students that have performed research on HE over the years.

Conflicts of Interest: The authors declare no conflict of interest.

$\begin{array}{ll}\text { Abbreviations } \\ \text { HE } & \text { Hepatic encephalopathy } \\ \text { ALF } & \text { Acute liver failure } \\ \text { AASLD } & \text { American Association for the Study of Liver Disease } \\ \text { EASL } & \text { European Association for the Study of the Liver } \\ \text { PSS } & \text { Portal-systemic shunt } \\ \text { ACLF } & \text { Acute-on-chronic liver failure } \\ \text { AISF } & \text { Italian Association for the Study of the Liver } \\ \text { ICU } & \text { Intensive care unit } \\ \text { DDEI } & \text { Dehydration/diuretics/electrolyte imbalance } \\ \text { CI } & \text { Confidence interval } \\ \text { MOF } & \text { Multi-organ failure }\end{array}$

\section{References}

1. Bustamante, J.; Rimola, A.; Ventura, P.J.; Navasa, M.; Cirera, I.; Reggiardo, V.; Rodés, J. Prognostic significance of hepatic encephalopathy in patients with cirrhosis. J. Hepatol. 1999, 30, 890-895. [CrossRef]

2. Cardoso, F.S.; Gottfried, M.; Tujios, S.; Olson, J.C.; Karvellas, C.J. Continuous renal replacement therapy is associated with reduced serum ammonia levels and mortality in acute liver failure. Hepatology 2018, 67, 711-720. [CrossRef]

3. Montagnese, S.; Bajaj, J.S. Impact of Hepatic Encephalopathy in Cirrhosis on Quality-of-Life Issues. Drugs 2019, 79, 11-16. [CrossRef]

4. Neff, G.W.; Kemmer, N.; Duncan, C.; Alsina, A. Update on the management of cirrhosis-focus on cost-effective preventative strategies. Clinicoecon. Outcomes Res. 2013, 5, 143-152. [CrossRef] 
5. Di Pascoli, M.; Ceranto, E.; De Nardi, P.; Donato, D.; Gatta, A.; Angeli, P.; Pontisso, P. Hospitalizations Due to Cirrhosis: Clinical Aspects in a Large Cohort of Italian Patients and Cost Analysis Report. Dig. Dis. 2017, 35, 433-438. [CrossRef]

6. Neff, G. Pharmacoeconomics of hepatic encephalopathy. Pharmacotherapy 2010, 30, 28S-32S. [CrossRef]

7. Amodio, P. Hepatic Encephalopathy: Historical Remarks. J. Clin. Exp. Hepatol. 2015, 5, S4-S6. [CrossRef]

8. Vilstrup, H.; Amodio, P.; Bajaj, J.; Cordoba, J.; Ferenci, P.; Mullen, K.D.; Weissenborn, K.; Wong, P.; Talwalkar, J.A.; Conjeevaram, H.S.; et al. Hepatic Encephalopathy in Chronic Liver Disease: 2014 Practice Guideline by the European Association for the Study of the Liver and the American Association for the Study of Liver Diseases. J. Hepatol. 2014, 61, 642-659. [CrossRef]

9. Zwingmann, C.; Desjardins, P.; Hazell, A.; Chatauret, N.; Michalak, A.; Butterworth, R.F. Reduced Expression of Astrocytic Glycine Transporter ( Glyt-1 ) in Acute Liver Failure. Brain 2002, 17, $263-273$.

10. Ferenci, P.; Lockwood, A.; Mullen, K.; Tarter, R.; Weissenborn, K.; Blei, A.T. Hepatic encephalopathy-Definition, nomenclature, diagnosis, and quantification: Final report of the Working Party at the 11th World Congresses of Gastroenterology, Vienna, 1998. Hepatology 2002, 35, 716-721. [CrossRef]

11. Haj, M.; Rockey, D.C. Ammonia levels do not guide clinical management of patients with hepatic encephalopathy caused by cirrhosis. Am. J. Gastroenterol. 2020, 115, 723-728. [CrossRef]

12. Ginès, P.; Fernández, J.; Durand, F.; Saliba, F. Management of critically-ill cirrhotic patients. J. Hepatol. 2012, 56, S13-S24. [CrossRef]

13. Riddell, A.G.; McDermott, W. V Hepatic coma. Lancet 1954, 266, 1263-1267. [CrossRef]

14. Hahn, M.; Massen, O.; Nencki, M.; Pawlow, J. Die Eek'sehe Fistel zwischen der unteren Hohlvene und tier Pfortader und ihre Folgen fiir den Organismus. Arch. Exp. Pathol. Pharm. 1893, 32, 161-210. [CrossRef]

15. Rohmer, F.; Kurtz, D. E.E.G et Ammoniémie dans les Troubles Nerveux das Affections Hépatiques. In Proceedings of the VII International Congress of Neurology; Societa Grafica Romana: Rome, Italy, 1961; pp. 115-163.

16. Matsumoto, S.; Häberle, J.; Kido, J.; Mitsubuchi, H.; Endo, F.; Nakamura, K. Urea cycle disorders-Update. J. Hum. Genet. 2019, 64, 833-847. [CrossRef]

17. Nardelli, S.; Gioia, S.; Ridola, L.; Riggio, O. Radiological Intervention for Shunt Related Encephalopathy. J. Clin. Exp. Hepatol. 2018, 8, 452-459. [CrossRef]

18. Zieve, L.; Olsen, R.L. Zieve-Gut,1977,18.688.pdf. Gut 1977, 18, 688-691. [CrossRef]

19. Layrargues, G.P.; Rose, C.; Spahr, L.; Zayed, J.; Normandin, L. Role of Manganese in the Pathogenesis of Portal-Systemic Encephalopathy. Brain 1998, 13, 311-317.

20. Carpenedo, R.; Mannaioni, G.; Moroni, F. Oxindole, a Sedative Tryptophan Metabolite, Accumulates in Blood and Brain of Rats with Acute Hepatic Failure. Control 1998, 1998-2003. [CrossRef]

21. Bolognesi, M.; Merkel, C.; Bianco, S.; Angeli, P.; Sacerdoti, D.; Amodio, P.; Gatta, A. Clinical significance of the evaluation of hepatic reticuloendothelial removal capacity in patients with cirrhosis. Hepatology 1994, 19, 628-634. [CrossRef]

22. Bernardi, M.; Moreau, R.; Angeli, P.; Schnabl, B.; Arroyo, V. Mechanisms of decompensation and organ failure in cirrhosis: From peripheral arterial vasodilation to systemic inflammation hypothesis. J. Hepatol. 2015, 63, 1272-1284. [CrossRef] [PubMed]

23. Cabrera-Pastor, A.; Llansola, M.; Montoliu, C.; Malaguarnera, M.; Balzano, T.; Taoro-Gonzalez, L.; García-García, R.; MangasLosada, A.; Izquierdo-Altarejos, P.; Arenas, Y.M.; et al. Peripheral inflammation induces neuroinflammation that alters neurotransmission and cognitive and motor function in hepatic encephalopathy: Underlying mechanisms and therapeutic implications. Acta Physiol. 2019, 226, 1-19. [CrossRef] [PubMed]

24. Tarantino, G.; Citro, V.; Esposit, P.; Giaquinto, S.; de Leone, A.; Milan, G.; Tripodi, F.S.; Cirillo, M.; Lobello, R. Blood ammonia levels in liver cirrhosis: A clue for the presence of portosystemic collateral veins. BMC Gastroenterol. 2009, 9, 1-11. [CrossRef] [PubMed]

25. Butterworth, R.F. Hepatic Encephalopathy in Cirrhosis: Pathology and Pathophysiology. Drugs 2019, 79, 17-21. [CrossRef] [PubMed]

26. Shawcross, D.L.; Davies, N.A.; Williams, R.; Jalan, R. Systemic inflammatory response exacerbates the neuropsychological effects of induced hyperammonemia in cirrhosis. J. Hepatol. 2004, 40, 247-254. [CrossRef] [PubMed]

27. Amodio, P.; Del Piccolo, F.; Pettenò, E.; Mapelli, D.; Angeli, P.; Iemmolo, R.; Muraca, M.; Musto, C.; Gerunda, G.; Rizzo, C.; et al. Prevalence and prognostic value of quantified electroencephalogram (EEG) alterations in cirrhotic patients. J. Hepatol. 2001, 35, 37-45. [CrossRef]

28. Bernuau, J.; Durand, F.; Werner, P.; Sauvanet, A.; Erlinger, S.; Belghiti, J. Acute liver failure. Lancet 1995, 345, 802.

29. Blei, A.T. Brain edema in acute liver failure: Can it be prevented? Can it be treated? J. Hepatol. 2007, 46, 564-569. [CrossRef]

30. Gupta, T.; Dhiman, R.K.; Ahuja, C.K.; Agrawal, S.; Chopra, M.; Kalra, N.; Duseja, A.; Taneja, S.; Khandelwal, N.; Chawla, Y. Characterization of Cerebral Edema in Acute-on-Chronic Liver Failure. J. Clin. Exp. Hepatol. 2017, 7, 190-197. [CrossRef]

31. Cordoba, J.; Ventura-Cots, M.; Simón-Talero, M.; Amorós, À.; Pavesi, M.; Vilstrup, H.; Angeli, P.; Domenicali, M.; Ginés, P.; Bernardi, M.; et al. Characteristics, risk factors, and mortality of cirrhotic patients hospitalized for hepatic encephalopathy with and without acute-on-chronic liver failure (ACLF). J. Hepatol. 2014, 60, 275-281. [CrossRef]

32. Labenz, C.; Toenges, G.; Huber, Y.; Nagel, M.; Marquardt, J.U.; Schattenberg, J.M.; Galle, P.R.; Labenz, J.; Wörns, M.A. Raised serum Interleukin-6 identifies patients with liver cirrhosis at high risk for overt hepatic encephalopathy. Aliment. Pharmacol. Ther. 2019, 50, 1112-1119. [CrossRef] [PubMed] 
33. Tapper, E.B.; Zhao, L.; Nikirk, S.; Baki, J.; Parikh, N.D.; Lok, A.S.; Waljee, A.K. Incidence and Bedside Predictors of the First Episode of Overt Hepatic Encephalopathy in Patients With Cirrhosis. Am. J. Gastroenterol. 2020, 1-9. [CrossRef]

34. Praktiknjo, M.; Simón-Talero, M.; Römer, J.; Roccarina, D.; Martínez, J.; Lampichler, K.; Baiges, A.; Low, G.; Llop, E.; Maurer, M.H.; et al. Total area of spontaneous portosystemic shunts independently predicts hepatic encephalopathy and mortality in liver cirrhosis. J. Hepatol. 2020, 72, 1140-1150. [CrossRef] [PubMed]

35. Vierling, J.M.; Mokhtarani, M.; Brown, R.S., Jr.; Mantry, P.; Rockey, D.C.; Ghabril, M.; Rowell, R.; Jurek, M.; Coakley, D.F.; Scharschmidt, B.F. Fasting Blood Ammonia Predicts Risk and Frequency of Hepatic Encephalopathy Episodes in Patients With Cirrhosis. Clin. Gastroenterol. Hepatol. 2016, 14, 903-906. [CrossRef] [PubMed]

36. Shalimar; Sheikh, M.F.; Mookerjee, R.P.; Agarwal, B.; Acharya, S.K.; Jalan, R. Prognostic Role of Ammonia in Patients With Cirrhosis. Hepatology 2019, 70, 982-994. [CrossRef]

37. Ali, M.H.; Kabir, M.A.; Islam, M.S.; Rahim, C.M.; Hasan, M.K.; Islam, M.K.; Hasan, M.R.; Alam, M.S. Study on Precipitating Factor of Chronic Hepatic Encephalopathy. Mymensingh Med. J. 2020, 29, 800-806.

38. Devrajani, B.R.; Shah, S.Z.A.; Devrajani, T.; Kumar, D. Precipitating factors of hepatic encephalopathy at a tertiary care hospital Jamshoro, Hyderabad. J. Pak. Med. Assoc. 2009, 59, 683-686.

39. Strauss, E.; da Costa, M.F. The importance of bacterial infections as precipating factors of chronic hepatic encephalopathy in cirrhosis. Hepatogastroenterology 1998, 45, 900-904.

40. Häussinger, D. Low grade cerebral edema and the pathogenesis of hepatic encephalopathy in cirrhosis. Hepatology 2006, 43, 1187-1190. [CrossRef]

41. Díaz-Fontenla, F.; Castillo-PraDillo, M.; Díaz-Gómez, A.; Ibañez-Samaniego, L.; Gancedo, P.; Guzmán-De-Villoria, J.A.; FernándezGarcía, P.; Bañares-Cañizares, R.; García-Martínez, R. Refractory hepatic encephalopathy in a patient with hypothyroidism: Another element in ammonia metabolism. World J. Gastroenterol. 2017, 23, 5246-5252. [CrossRef]

42. Asaki, Y.; Murofushi, Y.; Yasukawa, K.; Hara, M.; Takanashi, J. Neurochemistry of hyponatremic encephalopathy evaluated by MR spectroscopy. Brain Dev. 2020, 42,767-770. [CrossRef]

43. Bridwell, R.E.; Willis, G.C.; Gottlieb, M.; Koyfman, A.; Long, B. American Journal of Emergency Medicine Decompensated hypothyroidism: A review for the emergency clinician. Am. J. Emerg. Med. 2020, 39, 207-212. [CrossRef] [PubMed]

44. Zhao, L.; Gao, Y.; Guo, S.; Lu, X.; Yu, S.; Ge, Z.Z.; Zhu, H.D.; Li, Y. Sepsis-Associated Encephalopathy: Insight into Injury and Pathogenesis. CNS Neurol. Disord. Drug Targets 2020. [CrossRef] [PubMed]

45. Cadranel, J.F.; Lebiez, E.; Di V, M.; Bernard, B.; El, K.S.; Tourbah, A.; Pidoux, B.; Valla, D.; Opolon, P. Focal neurological signs in hepatic encephalopathy in cirrhotic patients: An underestimated entity? Am. J. Gastroenterol. 2001, 96, 515-518. [CrossRef] [PubMed]

46. Victor, M.; Adams, R.D.; Cole, M. The acquired (non-Wilsonian) type of chronic hepatocerebral degeneration. Medicine 1965, 44, 345-396. [CrossRef]

47. Weissenborn, K. Parkinsonism in patients with cirrhosis: Coincidence or consequence? Liver Int. 2011, 592-594. [CrossRef]

48. Sousa, A.L.; Salgado, P.; Alves, J.E.; Silva, S.; Ferreira, S.; Magalhães, M. Case Reports Uncommon Movement Disorders in Chronic Hepatic Disease with Response to Rifaximin. Tremor Other Hyperkinet. Mov. 2019, 9. [CrossRef]

49. Weissenborn, K.; Bokemeyer, M.; Krause, J.; Ennen, J.; Ahl, B. Neurological and neuropsychiatric syndromes associated with liver disease. Aids 2005, 19, 93-98. [CrossRef]

50. Amodio, P. Hepatic encephalopathy: Diagnosis and management. Liver Int. 2018, 38, 966-975. [CrossRef]

51. Helmes, E.; Østbye, T. Beyond memory impairment: Cognitive changes in Alzheimer's disease. Arch. Clin. Neuropsychol. 2002, 17, 179-193. [CrossRef]

52. Karpenko, A.; Keegan, J. Diagnosis of Coma. Emerg. Med. Clin. North Am. 2021, 39, 155-172. [CrossRef] [PubMed]

53. Wan, M.; Chase, J.M. Delirium in older adults: Diagnosis, prevention, and treatment. B. C. Med. J. 2017, 59, 165-170. [CrossRef]

54. Bello, V.M.E.; Schultz, R.R. Prevalence of treatable and reversible dementias A study in a dementia outpatient clinic. Dement. Neuropsychol. 2011, 5, 44-47. [CrossRef]

55. Amarenco, P. Transient Ischemic Attack. N. Engl. J. Med. 2020, 382, 1933-1941. [CrossRef] [PubMed]

56. Parikh, N.S.; Navi, B.B.; Schneider, Y.; Jesudian, A.; Kamel, H. Association between cirrhosis and stroke in a nationally representative cohort. JAMA Neurol. 2017, 74, 927-932. [CrossRef] [PubMed]

57. Montagnese, S.; Amodio, P. Hepatic Encephgalopathy Diagnosis Conundrum. In Diagnosis and Management of Hepatic Encephalopathy; Bajaj, J.S., Ed.; Springer International Publishing: Cham, Switzerland, 2018; pp. 117-125. ISBN 9783319767970.

58. Montagnese, S.; Russo, F.P.; Amodio, P.; Burra, P.; Gasbarrini, A.; Loguercio, C.; Marchesini, G.; Merli, M.; Ponziani, F.R.; Riggio, O.; et al. Hepatic encephalopathy 2018: A clinical practice guideline by the Italian Association for the Study of the Liver (AISF). Dig. Liver Dis. 2019, 51, 190-205. [CrossRef]

59. Qi, R.; Zhang, L.J.; Xu, Q.; Zhong, J.; Wu, S.; Zhang, Z.; Liao, W.; Ni, L.; Zhang, Z.; Chen, H.; et al. Selective impairments of resting-state networks in minimal hepatic encephalopathy. PLoS ONE 2012, 7, e37400. [CrossRef]

60. Zheng, G.; Zhang, L.J.; Zhong, J.; Wang, Z.; Qi, R.; Shi, D.; Lu, G.M. Cerebral blood flow measured by arterial-spin labeling MRI: A useful biomarker for characterization of minimal hepatic encephalopathy in patients with cirrhosis. Eur. J. Radiol. 2013, 82, 1981-1988. [CrossRef]

61. Cudalbu, C.; Taylor-Robinson, S.D. Brain Edema in Chronic Hepatic Encephalopathy. J. Clin. Exp. Hepatol. 2019, 9, 362-382. [CrossRef] 
62. Bajaj, J.S. Interaction of Bacterial Metagenome and Virome in Patients with Cirrhosis and Hepatic Encephalopathy. Gut 2019, 5, 1-12. [CrossRef]

63. Parsons-Smith, B.G.; Summerskill, W.H.; Dawson, A.M.; Sherlock, S. The electroencephalograph in liver disease. Lancet 1957, 273, 867-871. [CrossRef]

64. Conn, H.O.; Leevy, C.M.; Vlahcevic, Z.R.; Rodgers, J.B.; Maddrey, W.C.; Seeff, L.; Levy, L.L. Comparison of Lactulose and Neomycin in the Treatment of Chronic Portal-Systemic Encephalopathy: A double blind controlled trial. Gastroenterology 1977, 72, 573-583. [CrossRef]

65. Bajaj, J.S.; Cordoba, J.; Mullen, K.D.; Amodio, P.; Shawcross, D.L.; Butterworth, R.F.; Morgan, M.Y. Review article: The design of clinical trials in hepatic encephalopathy-an International Society for Hepatic Encephalopathy and Nitrogen Metabolism (ISHEN) consensus statement. Aliment. Pharmacol. Ther. 2011, 33, 739-747. [CrossRef]

66. Amodio, P.; Montagnese, S.; Gatta, A.; Morgan, M.Y. Characteristics of minimal hepatic encephalopathy. Metab. Brain Dis. 2004, 19, 253-267. [CrossRef]

67. Montagnese, S.; Amodio, P.; Morgan, M.Y. Methods for diagnosing hepatic encephalopathy in patients with cirrhosis: A multidimensional approach. Metab. Brain Dis. 2004, 19, 281-312. [CrossRef]

68. Schomerus, H.; Weissenborn, K.; Hecker, H.; Hamster, W.; Rückert, N. PSE-Syndrom-Test; Swets Test Services: Bielefeld, Germany, 1999.

69. Campagna, F.; Montagnese, S.; Ridola, L.; Senzolo, M.; Schiff, S.; De Rui, M.; Pasquale, C.; Nardelli, S.; Pentassuglio, I.; Merkel, C.; et al. The animal naming test: An easy tool for the assessment of hepatic encephalopathy. Hepatology 2017, 66, 198-208. [CrossRef]

70. Amodio, P.; Del Piccolo, F.; Marchetti, P.; Angeli, P.; Iemmolo, R.; Caregaro, L.; Merkel, C.; Gerunda, G.; Gatta, A. Clinical features and survival of cirrhotic patients with subclinical cognitive alterations detected by the number connection test and computerized psychometric tests. Hepatology 1999, 29, 1662-1667. [CrossRef]

71. Bajaj, J.S.; Saeian, K.; Verber, M.D.; Hischke, D.; Hoffmann, R.G.; Franco, J.; Varma, R.R.; Rao, S.M. Inhibitory Control Test Is a Simple Method to Diagnose Minimal Hepatic Encephalopathy and Predict Development of Overt Hepatic Encephalopathy. Am. J. Gastroenterol. 2007, 754-760. [CrossRef]

72. Bajaj, J.S.; Thacker, L.R.; Heuman, D.M.; Fuchs, M.; Sterling, R.K.; Sanyal, A.J.; Puri, P.; Siddiqui, M.S.; Stravitz, R.T.; Bouneva, I.; et al. The stroop smartphone application is a short and valid method to screen for minimal hepatic encephalopathy. Hepatology 2013, 58, 1122-1132. [CrossRef]

73. Lopez, O.L. Mild cognitive impairment. Continuum 2013, 19, 411-424. [CrossRef]

74. Sachdev, P.S.; Lipnicki, D.M.; Kochan, N.A.; Crawford, J.D.; Thalamuthu, A.; Andrews, G.; Brayne, C.; Matthews, F.E.; Stephan, B.C.M.; Lipton, R.B.; et al. The prevalence of mild cognitive impairment in diverse geographical and ethnocultural regions: The COSMIC Collaboration. PLoS ONE 2015, 10, e0142388. [CrossRef] [PubMed] 